\title{
The Spatial Patterns of Functional Groups and Successional Direction in a Coastal Dune Community
}

\author{
Rusty A. Feagin ${ }^{1}$ and X. Ben Wu ${ }^{2}$
}

Authors are ${ }^{1}$ Assistant Professor, Spatial Sciences Laboratory, Department of Ecosystem Science \& Management, Texas A $\mathrm{M}$ University, 1500 Research Pkwy., Ste. B223, College Station, TX 77845; and Professor, Department of Ecosystem Science \& Management, Texas A\&M University, 2126 TAMU, College Station, TX 77843.

\begin{abstract}
Various methods have been devised to classify plants into functional groups, yet little work has investigated how these groups differentially impact succession with spatially explicit mechanisms. In a sand dune plant community on Galveston Island, Texas, we categorized plants by their functional traits, mapped the topographical contours of the sand dunes as a first-order effect to describe the spatial distribution of environmental stress, and quantified the second-order within- and between-group associations of the plants within specific bands of these contours using Ripley's K analysis. We then quantified the influence of spatially explicit functional traits on the direction of succession over time. We found evidence that the spatial pattern of the plants at one time exerted an influence on the pattern of the plants at a later time, based on their functional traits, thereby influencing the direction of sand dune succession. This study describes the spatiotemporal mechanics that lie behind sand dune plant succession: a process that has been a classical example of facilitation for ecologists, a plant community that is at risk from global sea-level rise and hurricanes, and an important rangeland resource that is being restored around the world for its ecological, range production, and coastal protection value.
\end{abstract}

\section{Resumen}

Varios métodos han sido ideados para clasificar las plantas en grupos funcionales, pero pocos trabajos han investigado, con mecanismos espaciales explícitos, el impacto diferencial de estos grupos en la sucesión. En una comunidad vegetal de dunas de arena en la isla de Galveston, Texas, E.U.A. categorizamos las plantas por sus características funcionales y elaboramos un mapa de los contornos topográficos de las dunas de arena como el efecto de primer orden para describir la distribución espacial del estrés ambiental y cuantificamos como segundo orden las asociaciones entre y dentro de grupos de plantas con bandas específicas de estos contornos, para ello usamos el análisis $\mathrm{K}$ de Ripley. Después, cuantificamos la influencia de las características funcionales espacialmente explicitas sobre la dirección de la sucesión a través del tiempo. Encontramos evidencia de que el patrón espacial de las plantas en algún tiempo ejerció una influencia sobre el patrón posterior de las plantas, en base a sus características funcionales, por esta razón, influye en la dirección de la sucesión de las dunas de arena. Este estudio describe los mecanismos espcio-temporales que están atrás de la sucesión vegetal en las dunas de arena, un proceso que ha sido un ejemplo clásico de facilitación para los ecólogos, una comunidad vegetal que está en riesgo de un aumento global del nivel del mar y de los huracanes y un importante recurso que está siendo restaurado alrededor del mundo, tanto por su valor ecológico como por su valor de protección costero.

Key Words: amelioration, directionality, facilitation, point pattern analysis, Ripley's K, sand dunes, spatial analysis, spatial succession

\section{INTRODUCTION}

Sand dune plant communities have historically been the principal model for studying the effect of individual plants upon succession because of their relative simplicity and fast rates of change (Cowles 1899; Warming and Vahl 1909). These plant communities are distributed around the world, they protect valuable coastal property and infrastructure (Feagin 2005a), and they compose a large diversity of uniquely adapted plant species (Greipsson 2002). They have been historically impacted by overgrazing in many locations, especially along the Gulf Coast of the United States (Hester et al. 1994), and are

Correspondence: Dr Rusty Feagin, Spatial Sciences Laboratory, Dept of Ecosystem Science \& Management, Texas A\&M University, 1500 Research Pkwy, Ste B223, College Station, TX 77845. Email: feaginr@tamu.edu

Manuscript received 18 August 2006; manuscript accepted 4 May 2007. still used today as a major rangeland resource in Texas, where entire barrier islands are managed as cattle ranches. Unfortunately, many of these communities are at risk of sea-level rise caused by climate change (Feagin et al. 2005a) and increasingly strong hurricane disturbances (Emanuel 2005).

Spatial interactions among the plants are an essential component of sand dune succession with strong patterning of environmental gradients and mixed biotic interactions. On the beach, embryonic dunes form as sand is forced out of suspension by clumps of vegetation (Maun 1998; Poulson 1999), creating feedback that lends greater inertia to the successional process of progressive habitat amelioration and nucleation (Yarranton and Morrison 1974; Franks 2003a). As these embryonic dunes form due to sand deposition, they begin to coalesce (Martinez and Moreno-Casasola 1996). The location of each successional stage is often tied to the balance of facilitative forces relative to other physical factors, such as salt spray (Boyce 1954) and sand burial 
(Wilson and Sykes 1999), which results in a community that is arrayed in zones along the beach-land gradient (van Tooren et al. 1983; Moreno-Casasola 1988; Ehrenfeld 1990), with additional patterns that occur within these zones at a finer scale because of competition (Silander and Antonovics 1982; Lichter 2000; Franks 2003b).

Explicit spatial patterns of plants on sand dunes have been studied with relation to seed dispersal patterns (Owen et al. 2001), the location of water (Schat and Beckhoven 1991), and models of plant-to-plant interactions (Wiegand et al. 1998; Anand and Kadmon 2000), yet no research has investigated the effect of different functional groups upon the pattern formation process, using data from the field. Our hypothesis is that individual plants drive succession forward, with inertial strength based upon spatial distance and direction based upon their functional affiliation.

The objective of this study was to show that functional groups and their associated spatial patterns drive the direction of succession in a beach-sand dune community. We analyzed the spatial and temporal patterns of 3 functional groups along a gradient, with respect to within- and between-functional group associations.

\section{METHODS}

\section{Study Area}

A $1225-\mathrm{m}^{2}(35 \times 35 \mathrm{~m})$ plot was set up along a beach-sand dune gradient in Galveston Island, Texas (lat $29^{\circ} 12^{\prime} 36^{\prime \prime} \mathrm{N}$, long $\left.94^{\circ} 55^{\prime} 12^{\prime \prime} \mathrm{W}\right)$. Dunes in this area are relatively small, typically only $2-3 \mathrm{~m}$ in height, have relatively silty sands, are catastrophically disturbed about once every 6 years, and are characterized by rapid primary successional advancement.

The plot containing the sand dune plant community stretched from the summer berm on the open beach to the edge of the upland-coastal prairie community behind the dune ridge. Aerial photography from 1934 shows the plot area to be within a fenced pasture. The plot was also was fronted with a much wider beach that has since been lost due to erosion, as exacerbated by overgrazing and more recent housing developments. Well before our study, Uniola paniculata L. had disappeared from Galveston Island, and at our site in particular, which was the previous site of the Moody Mansion on West Beach (lat $29^{\circ} 12^{\prime} 36^{\prime \prime} \mathrm{N}$, long $94^{\circ} 55^{\prime} 12^{\prime \prime} \mathrm{W}$ ), because of historical overgrazing and an inability to subsequently reestablish because of low seed viability. Nomenclature follows Hatch et al. (1990).

Approximately 18 months before the study, tropical storm Francis disturbed the area, leaving only bare sand. No unusual disturbances occurred during the study period, and growing conditions were typical for the subtropical, humid coastal dunes of Texas.

The plot was sampled in March 2000 and March 2001. For each sample, the location and size of each discrete plant clump was mapped using graph paper and was then digitized into a geographic information system (GIS). The central points of the plant clumps were used for spatial analysis. The allowable error was less than $0.1 \mathrm{~m}$.

Plants that occurred at the plot included Amaranthus greggii S. Wats. (an annual herb), Cakile geniculata (B.L. Robins.)
Millsp. (an annual herb), Croton punctatus Jacq. (a perennial woody herb), Ipomoea pes-caprae (L.) R.Br. (a perennial stoloniferous herb), Panicum amarum Ell. (a perennial grass), Sesuvium portulacastrum (L.) L. (a semiannual succulent herb), Spartina patens (Ait.) Muhl. (a perennial grass), and Sporobolus virginicus (L.) Kunth (a semiannual grass). Nomenclature follows Hatch et al. (1990). These 8 species were the only ones that occurred within the plot, which is typical of the relatively low plant diversity found on primary dunes in Texas.

\section{Statistical Approach}

The single plot was used for all spatial analysis because that is the standard procedure for point pattern statistics (Diggle 1983 ) in the plant ecology literature (as introduced by Haase 1995; see also Wiegand and Moloney 2004 for an extensive review of ecological publications where the single-plot method is used). This plot was subdivided into irregular subregions that were based upon contour intervals where the mean sample clustering was "homogeneous" (Pierre et al. 2003) as described in the methods section below. In addition to the plot data, plants from several other locations were used for functional group analysis as described in the methods section and as is the typical procedure in the literature (Westoby 1998).

It is important to point out that the spatial statistics that we use in this article are quite different from typical analysis of variance (ANOVA) or regression as first envisioned by Fisher (see Feagin 2005b for a review and comparison). The goal in standard experimental-plot statistics is to determine whether the mean values of a given number of treatments are statistically different from one another. This necessitates the use of replicates (multiple plots per treatment) to separate the treatment means by showing that the variance of the replicates within the treatments is small, whereas it is large between the treatments. In contrast, the goal in spatial statistics is to quantify a pattern in a given area; the individual samples or "replicates" occur within the boundary of the given area, the number of these samples is already included in the relevant statistical equation, the divergence of each sample spatially from all other samples influences the statistical power, and the statistical significance of the pattern in the given plot area and confidence intervals are acquired through the construction of an empirical, Monte Carlogenerated distribution that is composed of replications of the plot and its constant number of samples. In the spatial statistics used in this article, we iterated the same number of point samples (several hundred for each functional group) as were found within the research plot with 1000 Monte Carlo simulations.

It is important to point out that this standard procedure provides a high degree of certainty about whether the spatial pattern is significant in the plot area, but it does not implicitly relate this pattern to its likelihood of occurrence throughout the rest of the world. In ANOVA, researchers often make the unjustified assumption that the estimated treatment mean, based upon the sampled replicates in the study, represents the true mean that exists in the rest of the world. To connect this assumption with the real world in a manner that would make 
a statistician happy, would require either sampling every possible sample in the world, or using "random" models, which are rarely used, rather than the typically used "fixed" ANOVA models (Lentner and Bishop 1993). Using spatial statistics, one could draw a similar analogy: imagine expanding the boundaries of our single plot around every sample plant from a particular species that exists in the world-only 1 plot would be used, but it would describe the true spatial pattern distribution of that species in the entire world. In practice, we must limit the size of our sample and make the assumption that our sampled data represents the true distribution when sampled in good faith, regardless of statistical method or model.

\section{Functional Groups}

Plant species that occurred in the plot were placed into functional groups based on a classification system similar to the leaf-height-seed (LHS) method (Westoby 1998) and previous work by Webb (1998). Although various other systems have been proposed to classify sand dune plants according to their functional type (Shao et al. 1996; GarciaMora et al. 1999; Garcia-Novo et al. 2004), the LHS method has not been applied in sand dune systems nor has it been used to classify plants according to their function in the successional process.

Further, the LHS method has primarily been used to classify plants collected at regional scales and has not yet been applied to plants within a single community. Because the LHS classification has been used as a quantifiable surrogate (Westoby et al. 2002; Lavergne et al. 2003) for the competitor-stress-ruderal classification system of Grime (Grime 1973, 1974, 2001), we used the LHS method to discern similar functional traits that are crucial to each stage in the successional sequence in a single plant community.

Although standard LHS procedure (Westoby 1998) calls for 5 plants, 10 plants were collected for each species. For all functional group analysis, plants were collected from within the plot site of the previous location of the Moody Mansion land on West Beach (lat $29^{\circ} 12^{\prime} 36^{\prime \prime} \mathrm{N}$, long 94 $55^{\prime} 12^{\prime \prime} \mathrm{W}$ ), as well as from 2 other sites on Galveston Island: East Beach (lat $29^{\circ} 19^{\prime} 44.4^{\prime \prime} \mathrm{N}$, long $\left.94^{\circ} 44^{\prime} 6^{\prime \prime} \mathrm{W}\right)$ and 37 th Street at the base of the Seawall (lat $29^{\circ} 16^{\prime} 48^{\prime \prime} \mathrm{N}$, long $94^{\circ} 48^{\prime} 10.8^{\prime \prime} \mathrm{W}$ ). Once the plants were collected, 18 typical leaves were harvested from the individuals. The leaves were dried, measured for their area, and weighed to calculate the specific leaf area (SLA) index. For each of the species, the height of the 10 individuals was also measured as the length between the ground and the reach of the highest leaf when extended. Several hundred seeds were dried and weighed for each species. The total weight was then divided by the number of seeds to obtain the average seed weight. The average seed weight metric gave a more accurate value (Sartorius MC21S Micro Balance, Precision Weighing Balances, Bradford, MA) than standard LHS procedure, with the total number of seeds used for each species' estimate ranging up to 300 for the smallest seeds. One drawback to the LHS procedure is that it does not account for trade offs between rhizomatous vs. seed-based dispersal strategies; we took this into account when grouping the plants. The measurement data was then graphed on 3 nonlogarithmic axes to maximize apparent variances because our procedure also differed from standard LHS procedure in that it was concerned with a single plant community, rather than regional plant distributions. All other procedures followed Westoby (1998).

\section{Elevation Pattern and First-Order Effects}

We recorded the topography of the research plot with survey equipment (Leica Geosystems, St. Gallen, Switzerland) in March 2001. Using a GIS, we interpolated locations between these points based upon the inverse-distance method (ArcView 9.1, ESRI, Redlands, California) with a weight $(w)$ based upon a power function of the distance $(d)$ between a known point and the unknown interpolated location, specifically $w=1 / d^{2}$ in this analysis. Using the interpolated map, we then generated contour lines at every $30 \mathrm{~cm}$ in elevation.

Using the spatially explicit plant location data and the topographical data, we first investigated whether the functional groups were distributed at specific locations or elevations along the berm-to-dune ridge gradient. Plant distribution in dunes has been found to be strongly tied to this factor in previous research (Pierce and Kershaw 1975), and most other environmental factors on the dunes have been noted as a basic function of dune topography (Oosting and Billings 1942), such as the amount of salt spray and sand abrasion that reach the plants (Oosting 1945), water availability and soil moisture (Hartog et al. 1992), and tidal inundation (van der Veen et al. 1997). Soil structure, organic matter, and sediment grain sizes have also been shown to be dependent upon transient dune structures (Psuty 1992).

With the topography mapped as a first-order approximation to the spatial distribution of the functional groups, we were then able to use this map to define selected regions for subsequent second-order point-pattern analyses. We executed all second-order analyses only within the bounds that were appropriate for each functional group, based upon the firstorder distribution. For example, an analysis of the relationship between individual plants in one group and a second group could only take place within the elevation contours in which they were typically found and held in common. This method assumes spatial homogeneity within the bounds of the elevation ranges, which is reasonable considering that a particular functional group could grow anywhere within these ranges during the 2000-2001 period and that there were no other soilor habitat-based restrictions to this growth.

The use of these contours created irregular regions for the subsequent second-order analyses (Pelissier and Goreaud 2001) by using a map of the environment itself (Wiegand and Moloney 2004), and enabled exploration into potential interactions at finer scales.

\section{Point-Pattern and Second-Order Effects}

Multiple-scale spatial pattern of each functional group, as well as patterns of spatial association between groups, were quantified using Ripley's K function (Ripley 1976; Ripley 1981; Diggle 1983; Haase 1995) based on locations of the central points of individual plants (Haase et al. 1996; Moeur 1997) within their appropriately defined elevation contours. Ripley's K function is a second-order statistic that describes the tendency of points to be distributed in clumped, random, or hyperdispersed patterns at multiple scales. 
Table 1. Plant species from the sand dune plant community on Galveston Island, Texas, their functional group assignment, their seasonality, the typical location in which they grow upon the sand dunes, and their measurements using the adaptation of the leaf-height-seed (LHS) method for the community level. The term backbeach refers to the area immediately landward of the summer/winter berms and immediately seaward of the embryonic dunes. SLA indicates specific leaf area.

\begin{tabular}{lccccc}
\hline \multicolumn{1}{c}{ Plant species } & Functional group & Seasonality & Typical location & Height $(\mathrm{cm})$ & Seed $(\mathrm{g})$ \\
\hline Amaranthus gregii & colonizer & annual & backbeach & 36.1 & 0.000222 \\
Cakile geniculata & colonizer & annual & backbeach & 28.8 & 0.0049 \\
Sporobolus virginicus & colonizer & semiannual & backbeach & 11.2 & 0.000173 \\
Sesuvium portulacastrum & colonizer & semiannual & backbeach & 5.5 & 0.000481 \\
Ipomoea pes-caprae & soil binder & semiannual & embryonic dunes & 3.8 & 0.12184 \\
Croton punctatus & soil binder & semiannual & embryonic dunes/ridge & 41 & 35.8984 \\
Spartina patens & competitor & perennial & embryonic dunes/ridge & 68.3 & 0.023592 \\
Panicum amarum & competitor & perennial & dune ridge & 77.5 & 0.000042 \\
\hline
\end{tabular}

The univariate form of the function, for quantifying the point pattern of a single variable, is defined as

$$
\hat{K}(d)=\frac{|A|}{n^{2}} \sum_{i \neq j} \sum w_{i j}^{-1} I_{d}\left(u_{i j}\right)
$$

where $\hat{K}(d)$ is the $\mathrm{K}$ function value at distance (scale) $d, A$ is the area of a plot, $n$ is the number of points in the plot, $w_{i j}$ is the weight for edge correction, $I(d)$ is a variable that equals 1 if each $u_{i j}$ is less than $d$ and 0 otherwise, and $u_{i j}$ is the distance between points $i$ and $j$ (Haase 1995). The point pattern of one variable with respect to the distribution of another variable, or the spatial association between the 2 variables, can be quantified using the bivariate version of Ripley's K function:

$$
\hat{K}_{12}(d)=\frac{|A|}{n_{1} n_{2}} \sum_{i}^{n_{1}} \sum_{j}^{n_{2}} w_{i j}^{-1} I_{d}\left(u_{i j}\right)
$$

where $\hat{K}_{12}(d)$ is the bivariate $\mathrm{K}$ function value at distance $d$, $n_{1}$ is the number of points of variable 1 , and $n_{2}$ is the number of points of variable 2 . The $\mathrm{K}$ function is often converted to a linearized function $L(d)=\sqrt{\hat{K}(d) / \pi}$, and $L(d)-d$ is plotted against $d$ to facilitate interpretation (Skarpe 1991). One thousand Monte Carlo simulations were used to statistically assess the deviation of a pattern from a null model, where spatial locations of the points are randomly rearranged. The $\mathrm{K}$ function is then calculated at multiple scales for each of the random patterns to generate confidence intervals. $\mathrm{K}$ function values outside these intervals are significantly nonrandom, with positive values corresponding to aggregation, and negative values corresponding to hyperdispersion.

Univariate Ripley's K values were calculated for each functional group to quantify its scale-dependent spatial pattern in March 2000. For univariate null models, we used complete spatial randomness (CSR) for the points within the bounds of the appropriate elevation range.

Bivariate Ripley's $\mathrm{K}$ analyses were conducted to quantify scale-dependent spatial association between different functional groups in March 2000. For bivariate null models where the
2 patterns had both occurred during March 2000, we assumed CSR for both patterns only within those regions where the 2 patterns' elevation ranges had intersected. These bivariate analyses, however, could not provide information on successional mechanisms, i.e., directions of interactions between 2 functional groups, which led to patterns of spatial association, or spatial association of patterns of the same group over time.

To gain insight into the directions of interactions, crossbivariate Ripley's $\mathrm{K}$ analyses between patterns in successive seasons (March 2000 and March 2001) were conducted to quantify within-functional group and between-functional group directional associations. For cross-bivariate null models, we assumed "antecedent conditions" (Wiegand and Moloney 2004), where the dependency of the second set of points is tested relative to the fixed positions of the first, only within the elevation ranges where the 2 patterns occur after the first-order effect had been removed. Results of these analyses helped to assess the influence of the plant distribution of a functional group on the plant distribution of the same group or other groups in the next season, and to evaluate the role of each group or the direction and relative magnitude of its contribution in succession.

All univariate and bivariate analyses were conducted with Programita (Thorsten Wiegand, UFZ Centre for Environmental Research Leipzig-Halle, 2004) using the edge-correction methods of Getis and Franklin (1987) and the updated Goreaud and Pelissier methods (1999).

\section{RESULTS}

\section{Functional Groups}

The results of the functional group analysis show that plant characteristics are adapted to specific portions of the environmental gradient. As one moves up the beach toward the dune ridge, traits of seasonality move from annual to perennial (Table 1). Further, height decreases toward the low foot of the dune ridge, where there are embryonic dunes, and then increases as one moves up toward the top of the dune ridge. Seed weight follows an inverse pattern, increasing toward the embryonic dunes, then abruptly dropping off. When graphed according to the modified LHS method, the results show that the plants form 3 basic groups (Fig. 1). 


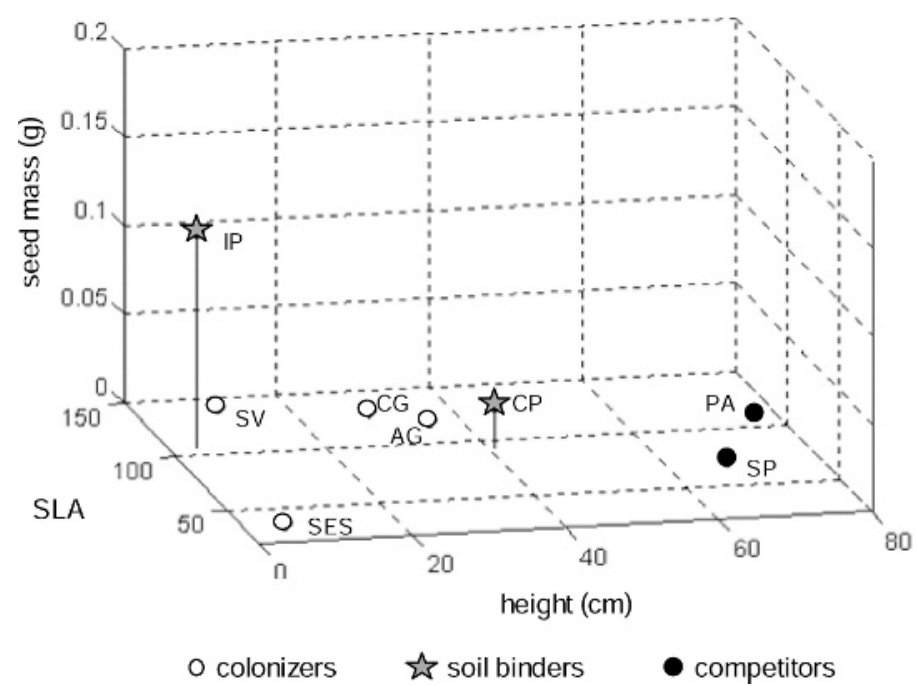

Figure 1. The 3 functional groups, as outlined by the adaptation of the leaf-height-seed (LHS) method for the community level. The early succession colonizing species (Amaranthus greggii [AG], Cakile geniculata [CG], Sesuvium portulacastrum [SES], and Sporobolus virginicus [SV]) have relatively low seed mass and low height values. The middle succession soil-binding species (Croton punctatus [CP] and Ipomoea pes-caprae [IP]) have relatively high seed mass and low height values. The late-succession competitor species (Panicum amarum [PA] and Spartina patens [SP]) have relatively low seed mass and tall height values.

We named these groups according to their community-level, functional equivalent of Grime's competitor-stress-ruderal strategy scheme. It is important to note that our definitions of colonizers, soil binders, and competitors are relative within the context of the coastal dunes, where all of the species could be classified as "colonizers" when compared with species from other plant communities. Our definitions would also collapse into a single category when using methods of classification intended for regional studies, such as the standard LHS method.

\section{Elevation and the Stress Gradient}

We found the 3 functional groups to be associated with specific ranges in elevation (Fig. 2A) over the course of the entire study period. This topographical gradient exhibited complexity along both the cross-shore direction as well as the long-shore direction. With the topography mapped (Fig. 2B) as a firstorder approximation to the spatial distribution of the functional groups, we were then able to use this map to define selected regions for subsequent second-order point-pattern analyses.

\section{Spatial Interactions}

Univariate Ripley's K analyses based on March 2000 data show that the spatial distribution of the colonizer functional group was random at small scales $(<0.25 \mathrm{~m})$ but significantly clumped at larger $(0.25-5 \mathrm{~m})$ scales (Fig. $3 \mathrm{~A})$. The small-scale random distribution, at $<0.25 \mathrm{~m}$, is accordant with the average radius within which plant density was greatest surrounding an individual plant. Spatial distributions of the soil-binder functional group (Fig. 3B) were similar except that
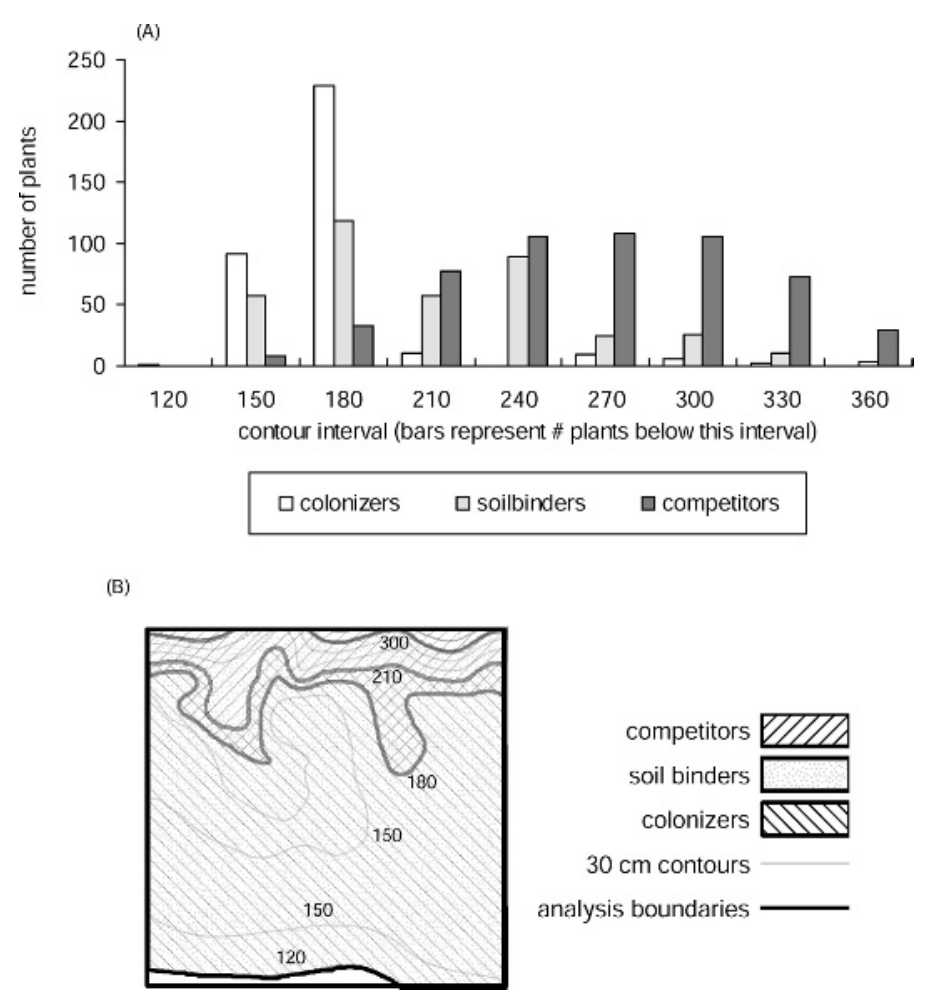

Figure 2. A, Plant distributions along the elevation gradient over the entire 2000 to 2001 study period. B, The topography of the plot. Outlined boundaries represent the irregular regions used in the subsequent Ripley's K analysis.

the clumping began at distances $<0.25 \mathrm{~m}$, potentially indicating an ability to tolerate overlapping plant structures. However, the competitor plants (Fig. 3C) were typically found growing at the highest density of the 3 groups $(0.61$ plants $\cdot \mathrm{m}^{-2}$ vs. 0.32 plants $\cdot \mathrm{m}^{-2}$ for colonizers and 0.33 plants $\cdot \mathrm{m}^{-2}$ for soil binders in the appropriate contour subzones of each group), yet they were homogeneously random within the relatively small areas of the plot occupied by the highest elevation ranges $(>180 \mathrm{~cm})$.

Bivariate Ripley's K analyses based on March 2000 data show contrasting spatial relationships among plants of different functional groups. Colonizers were negatively associated with soil-binder plants at scales $>1 \mathrm{~m}$ (Fig. 3D), indicating significant spatial segregation between colonizers and soil binders at these scales.

There were not a sufficient number of homogeneously distributed plants growing at common elevations to determine the second-order association between the colonizers and competitors (Fig. 3E). Simply put, their segregation could be described by the first-order gradient effect alone (Fig. 2A). This segregation into 2 different zones has also been observed at other sites as well.

We also found no second-order association between spatial distributions of soil-binder and competitor plants at scales $<5 \mathrm{~m}$ (Fig. 3F). However, there was some positive spatial association based upon the larger scale first-order phenomena of the elevation and stress gradient (Fig. 2A) because these 2 functional groups were both distributed between the $180-\mathrm{cm}$ and $300-\mathrm{cm}$ contours. 

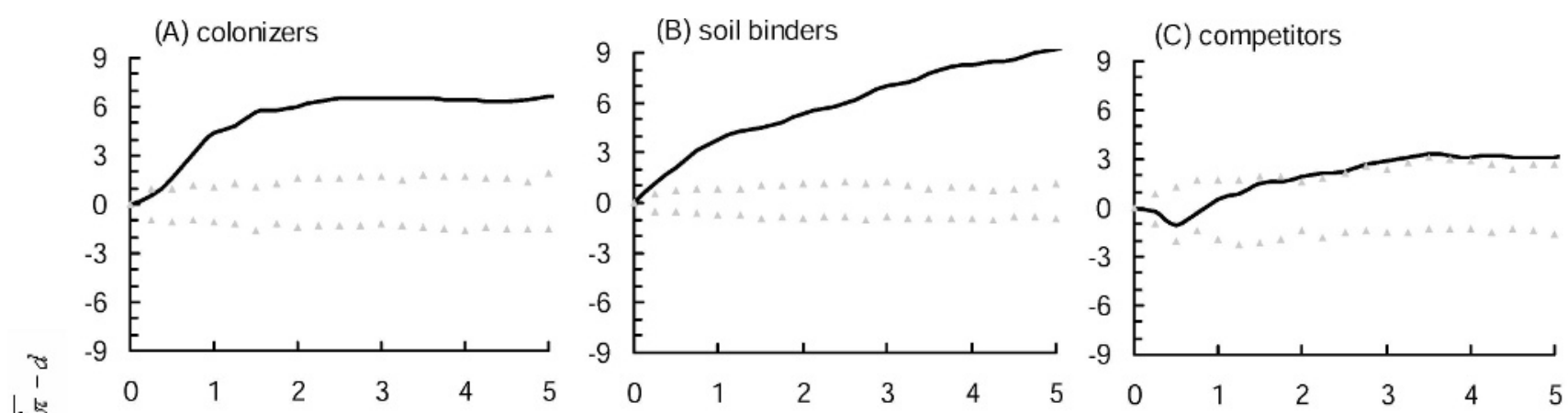

(D) colonizer vs. soil binders

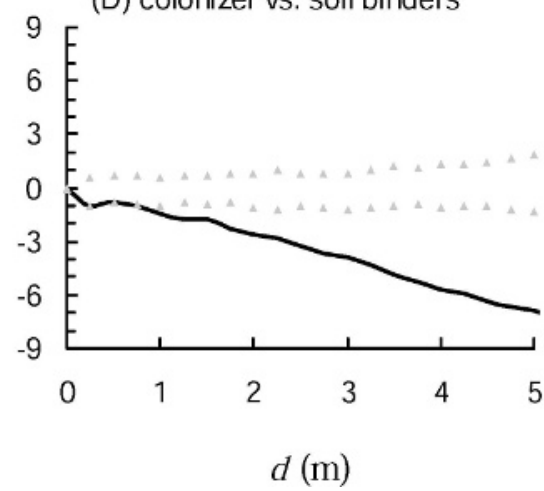

(E) colonizers vs. competitors

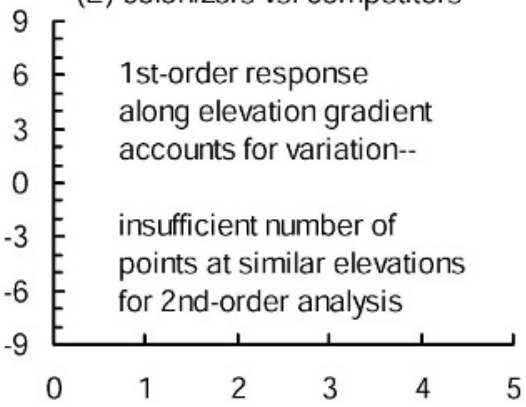

(F) soil binders vs. competitors

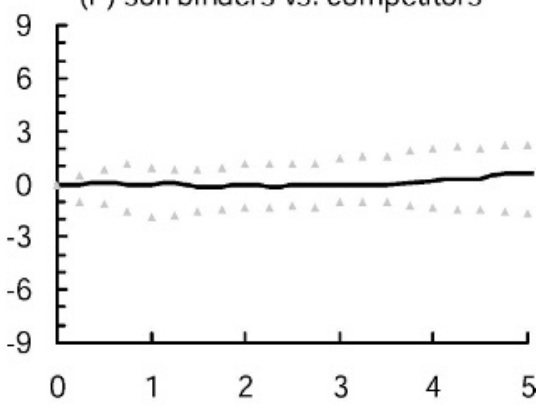

Figure 3. Ripley's K function results for A-C, within-functional group, and D-F, between-functional group associations. Results are plotted as $\sqrt{\hat{K}(d) / \pi}-d$ against $d$, where $\hat{K}(d)$ is the $\mathrm{K}$ function value at distance $d$. The solid line is the sample statistic, and the dotted lines indicate the $95 \%$ confidence interval. Values that fall outside the dotted lines indicate significantly nonrandom patterns, with greater values indicating clumped patterns and lesser values indicating regular (hyperdispersed) patterns.

Information on directional spatial interactions within and between functional groups was provided by the cross-bivariate Ripley's K analyses using March 2000 and March 2001 data (Fig. 4). Colonizers were positively associated with the colonizers of the next season at all but the smallest $(\leq 1.5 \mathrm{~m})$ scales (Fig. 4A). Interestingly, there was no spatial association between the colonizers and the soil-binder plants of the next season at any scale (Fig. 4B), contrary to their significant negative association when growing in the same 2000 season. Only 8 competitor plants in 2000 and 10 colonizers in 2001 grew in the common $180-\mathrm{cm}$ to $210-\mathrm{cm}$ contour elevation range, whereas only 1 colonizer plant in 2000 and 32 competitors in 2001 grew at the same elevation. These numbers of points were insufficient for second-order analyses (Fig. 4C).

The soil-binder plants were negatively associated with the colonizer (Fig. 4D) plants of the next season at scales $<1 \mathrm{~m}$. They had no significant spatial association with the soil-binder plants of the next season (Fig. 4E), contrary to their clumped univariate distribution in the March 2000 season. They were not significantly associated with the competitor plants (Fig. 4F) of the next season.

The segregation of the competitor functional group from the colonizer group of the following season into 2 different areas of the plot (Fig. 2A and 2B) resulted in a lack of enough points among these 2 groups to compare their patterns (Fig. 4G). However, there were elevation ranges where soil-binder plants in March 2000 and competitor plants of March 2001 had been colocated, yet there was no second-order association between them (Fig. 4H). Competitor plants were positively associated with the competitor plants of the next season at all scales
$>0.25 \mathrm{~m}$ (Fig. 4I). Again, this $0.25-\mathrm{m}$ distance is accordant with the average radius within which the highest density of plants often grew.

\section{DISCUSSION}

\section{Functional Group Affiliation Determines Pattern Response}

There was strong patterning in the spatial distribution of functional groups along the elevation gradient. In particular, the colonizers grew at low elevations, in sand with little organic matter, and in high-wind stress, high-disturbance locations; the soil binders grew at moderate elevations on embryonic dunes where the sand was buffered by organic matter; the competitors grew on well-developed dune ridges, in areas of dense plant growth. The response of the plants was first ordered along this gradient; it could be used as a coarse determinant of their spatial distribution.

\section{Functional Group Affiliation Determines Pattern Force}

Second-order interactions also appeared to be basic to the processes on the dunes. Both the colonizer and soil-binder functional groups grew in within-group clumps. It is quite possible that had there been any topographically related, smallscale environmental effect upon the tendency to clump, the plants had created these features in the shifting sands themselves (Goldsmith 1973).

These within-group clumps were significantly segregated from those of the opposing functional group at scales $>1 \mathrm{~m}$, during the same year. Segregation also occurred between the 

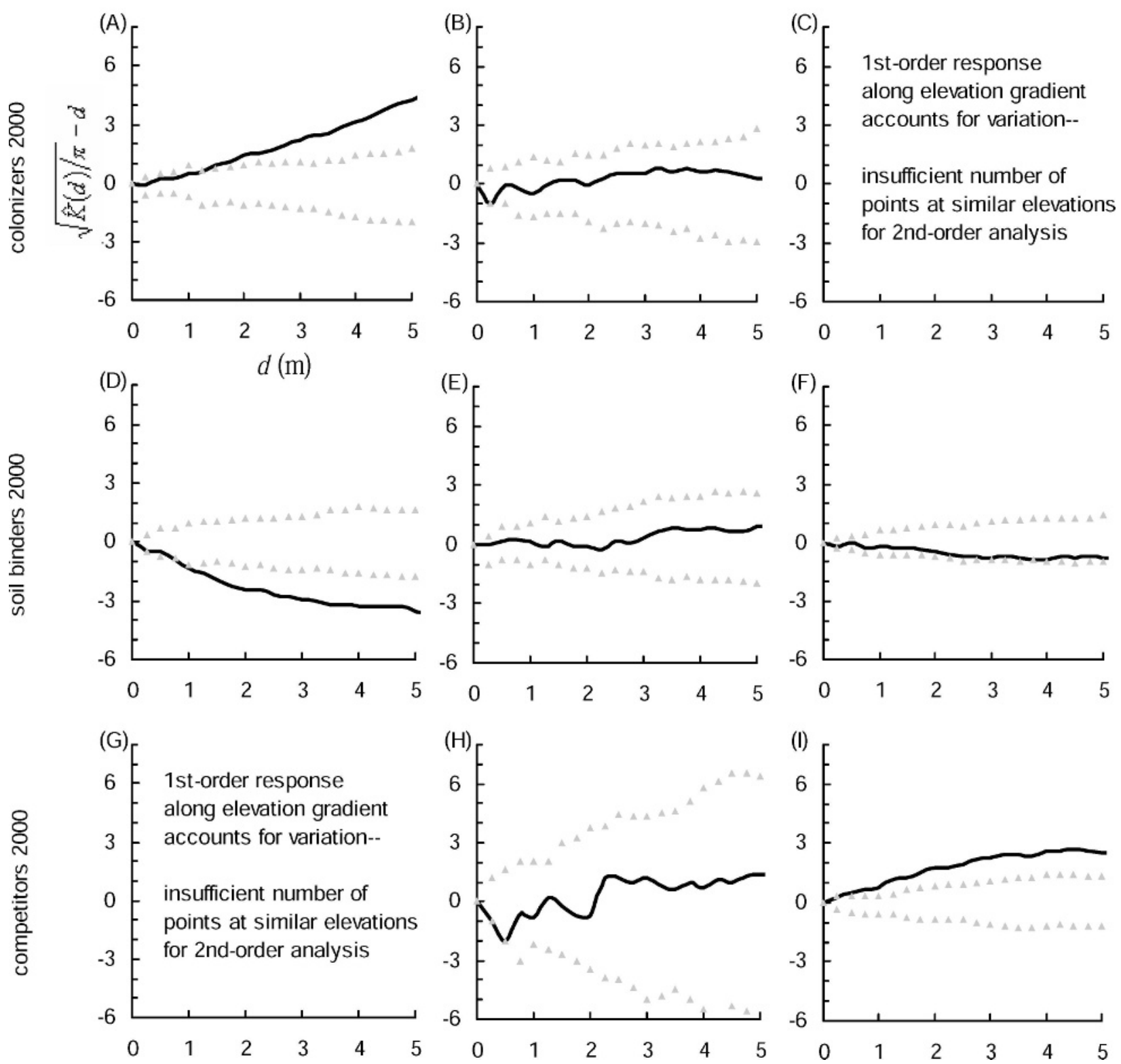

Figure 4. A-I, Cross-bivariate Ripley's K function results for functional groups from 2 consecutive seasons. Results are plotted as $\sqrt{\hat{K}(d) / \pi}-d$ against $d$, where $\hat{K}(d)$ is the $\mathrm{K}$ function value at distance $d$. Values that fall outside the dotted lines (greater or lesser values) indicate significantly nonrandom patterns, with greater values indicating clumped patterns and lesser values indicating regular (hyperdispersed) patterns.

locations of the soil binders in 2000 and the colonizers in 2001, yet this negative association did not exist in the opposite direction between the colonizers in 2000 and the soil binders in 2001, suggesting a loose colonizer-to-soil binder direction in the successional process. This directional movement was likely due to ameliorated environmental conditions rather than direct facilitative interactions because the colonizer-to-soil binder interactions at the $<1$-m scale were consistently random across all pattern analyses.

The competitors only exhibited 1 directional relationship. They were positively associated with new within-group arrivals at scales $>0.25 \mathrm{~m}$.

Additionally, colonizers and competitors did not grow in the same zones during the same year. This strong segregation pointed to a differential response to the environmental gradient over time, rather than between-group interactions, as a force in pattern formation. This spatiotemporal pattern is likely an artifact of the 2-year temporal scale of the study, and future work should further explore the potential that colonizers may indirectly affect future growth of competitors at the same spatial location over larger timescales.

\section{Direct Individual-Level Facilitation or Indirect Community-Level Amelioration?}

Because of the potential impact upon the theory of individualvs. community-level dynamics (Clements 1928 versus Gleason 
1926; Phillips 1934; Austin and Smith 1989; Callaway 1997), it is important to isolate the difference between direct individuallevel facilitation and indirect community-level amelioration. Are plants responding to fellow plants providing a local effect, such as a wind block, or are they responding to a topographic dune structure that was historically shaped by the entire plant community? The difference is one of time.

In greenhouse-based experimental work coupled with this study (Feagin and Wu 2005), we have shown that direct plantto-plant interaction forms small-scale patterns among plants in this dune community. Franks and Peterson (2003) have also shown that these same plants facilitate one another at small scales by mediating processes of sand burial.

At larger scales, we have shown that temporally indirect mechanisms drive the dynamics in this community (Feagin et al. $2005 \mathrm{~b}$ ). We have found that direct facilitation is a response to the conditions within a plant's sphere of influence as influenced by other plants balanced against the environment, whereas indirect community-level amelioration requires a glimpse into the temporal history of the community at all spheres of influence and a propagation of the successional inertia across space as time advances. In the future, manipulative experiments may be able to further elucidate some forms of temporal causality using the same descriptive statistics that we used in this study (Haase 2001).

\section{Dune Succession Is a Spatial Process That Is Driven by Functional Groups}

Pattern and process are tightly interwoven (Watt 1947) in rapidly organizing sand dune plant communities, where spatial patterns of environmental stress and the competition-facilitation balance (Pugnaire and Luque 2001) lead to individual-level responses (selection for plants with certain functional attributes at specific locations) and community-level forces (modification of the clumping intensity along the gradient). Environmental stress, biotic interactions, and community-level ameliorative forces together delimited the spatial pattern of the successional sand dune plant community through differential plant responses to these factors as governed by the traits of the functional groups. The spatial pattern of plants at one time exerts an influence on the pattern of plants at a later time based on the rules of function and strategy, forcing the directional changes in sand dune succession.

\section{MANAGEMENT IMPLICATIONS}

An understanding of the spatial pattern in which plants are growing is important for restoring sand dune plant communities, particularly because these areas are often used as grazing lands along the Gulf Coast (Hester et al. 1994), and their erosion in some locations may be due to overgrazing. It is often desirable to "jump-start" succession, and in the ideal circumstance, a manager would like to provide minimal effort for maximum return in plant community development. Our findings confirm that sand dune plants tend to grow in clumps with plants of the same functional group, yet these clumps are spatially segregated from the clumps of other functional groups. This result would imply a loose linkage in succession, meaning that a rangeland manager cannot plant the early stages of succession and expect the community to rapidly progress.

In fact, restoration of these coastal dune systems often involves directly planting the later stages of succession (Feagin 2005a). Once these later perennial groups are planted, they tend to increase within-group clumping, thereby providing maximal plant cover throughout the year. If the functional groups associated with later stages of succession (i.e., the competitor plants) are not planted as an intervention step, only a sparse cover of annuals (i.e., the colonizer plants) will exist, and the dunes will be largely unvegetated during the winter months. Without vegetation, large dune ridges do not form, and sand movement goes undeterred, resulting in the loss of habitat and shoreline protection value.

Spatial pattern does appear to be crucial to a plant's 1) response to its environment, 2) direct influence on other plants through interactions, or 3) indirect temporal influence upon community-level successional processes. Thus, rangeland managers and restoration ecologists should not only be mindful of whether a plant will grow well in a specific location but also how that plant will impact future development of the community. Coastal dunes provide a unique glimpse into the importance of all 3 spatially explicit processes in a rapidly progressing rangeland system. They also provide a relatively simple model for understanding how functional groups affect spatial succession in other rangeland plant communities, where the same dynamics are likely to occur in a less-obvious manner.

\section{LITERATURE CITED}

Anand, M., AND R. Kadmon. 2000. Community-level analysis of spatiotemporal plant dynamics. Ecoscience 7:101-110.

Austin, M. P., And T. M. Smith. 1989. A new model for the continuum concept. Vegetatio 83:35-47.

Boyce, S. G. 1954. The salt spray community. Ecological Monographs 24:29-67.

Callaway, R. M. 1997. Positive interactions in plant communities and the individualistic-continuum concept. Oecologia 112:143-149.

Clements, F. E. 1928. Plant succession: analysis of the development of vegetation. Washington, DC: Carnegie Institute. Publication 242.

CowLEs, H. C. 1899. The ecological relations of the vegetation of the sand dunes of Lake Michigan. Botanical Gazette 27:95-117, 167-202, 281-308, 361-391.

DIGGLE, P. J. 1983. Statistical analysis of spatial point patterns. London, United Kingdom: Academic Press. 159 p.

Ehrenfeld, J. G. 1990. Dynamics and processes of barrier island vegetation. Critical Reviews in Aquatic Science 2:437-480.

Emanuel, K. 2005. Increasing destructiveness of tropical cyclones of the last 30 years. Nature 436:686-688.

FeaGin, R. A. 2005a. Artificial dunes created to protect property on Galveston Island, Texas: the lessons learned. Ecological Restoration 23:89-94.

FEAGIN, R. A. 2005b. Heterogeneity versus homogeneity: a conceptual and mathematical theory in terms of scale-invariant and scale-covariant distributions. Ecological Complexity 2:339-356.

Feagin, R. A., D. J. Sherman, and W. E. Grant. 2005a. Coastal erosion, global sealevel rise, and the loss of sand dune plant habitats. Frontiers in Ecology and the Environment 3:359-364.

Feagin, R. A., And X. B. Wu. 2005. An experimental approach for quantifying the spatial interactions of plants under different treatment conditions. Ecoscience 21:44-52.

Feagin, R. A., X. B. Wu, F. E. Smeins, S. G. Whisenant, and W. E. Grant. $2005 \mathrm{~b}$. Individual versus community processes and pattern formation in a model of sand dune succession. Ecological Modelling 183:435-449. 
Franks, S. J. 2003a. Facilitation in multiple life-history stages: evidence for nucleated succession in coastal dunes. Plant Ecology 168:1-11.

Franks, S. J. 2003b. Competitive and facilitative interactions within and between 2 species of coastal dune perennials. Canadian Journal of Botany 8:330-337.

Franks, S. J., and C. J. Peterson. 2003. Burial disturbance leads to facilitation among coastal dune plants. Plant Ecology 168:13-21.

Garcia-Mora, M. R., J. B. Gallego-Fernandez, and F. Garcia-Novo. 1999. Plant functional types in coastal foredunes in relation to environmental stress and disturbance. Journal of Vegetation Science 10:27-34.

Garcia-Novo, F., M. C. Antunez-Barradas, M. Z. Gonzalez, J. B. Fernandez, and M. R. Garcia-Mora. 2004. Plant functional types in coastal dune habitats. In: M. L. Martinez and N. P. Psuty [EDS.]. Coastal dunes, ecology and conservation. Berlin, Germany: Springer-Verlag. p. 155-169.

Getis, A., And J. Franklin. 1987. Second-order neighborhood analysis of mapped point patterns. Ecology 68:473-477.

GLEASON, H. A. 1926. The individualistic concept of the plant association. Bulletin of the Torrey Botanical Club 53:1-20.

GoldSMITH, V. 1973. Internal geometry and origin of vegetated coastal sand dunes. Journal of Sedimentary Petrology 43:1128-1142.

Goreaud, F., and R. Pelissier. 1999. On explicit formulas of edge effect correction for Ripley's K-function. Journal of Vegetation Science 10:433-438.

GreIPsson, S. 2002. Coastal dunes. In: A. J. Davy and M. R. Perrow [eds.]. Handbook of ecological restoration: restoration in practice. Volume 2. Cambridge, United Kingdom: Cambridge University Press. p. 214-237.

Grime, J. P. 1973. Competitive exclusion in herbaceous vegetation. Nature 242:344-347.

GrIme, J. P. 1974. Vegetation classification by reference to strategies. Nature 250:26-31.

Grime, J. P. 2001. Plant Strategies, Vegetation Processes, and Ecosystem Properties. New York, NY: John Wiley. $417 \mathrm{p}$.

HAASE, P. 1995. Spatial pattern analysis in ecology based on Ripley's K function: introduction and methods of edge correction. Journal of Vegetation Science 6:575-582

HAASE, P. 2001. Can isotropy vs. anisotropy in the spatial association of plant species reveal physical vs. biotic facilitation? Journal of Vegetation Science 12:127-136.

Haase, P., F. I. Pugnaire, S. C. Clark, and L. D. Incoll. 1996. Spatial patterns in a two-tiered semi-arid shrubland in Southeastern Spain. Journal of Vegetation Science 7:527-534.

Hartog, M., F. van der Meulen, and J. Jongejans. 1992. Dune landscape development and changing groundwater regime: quantitative landscape succession with help of a GIS. In: R. G. Carter, T. F. Curtis, and M. J. Sheehy-Skeffington [EDS.]. Coastal dunes. Rotterdam, Amsterdam: A. A. Balkema. p. 119-127.

Hatch, S. L., K. N. Gandhi, And L. E. Brown. 1990. Checklist of the vascular plants of Texas. College Station, TX: Texas Agricultural Experiment Station. Available at: http://www.csdl.tamu.edu/ erich/web/plants.html. Accessed 12 June 2007.

Hester, M. W., Wilsey, B. J., and I. A. Mendelssohn. 1994. Grazing of Panicum amarum in a Louisiana barrier island dune plant community: management implications for dune restoration projects. Ocean and Coastal Management 23:213-224.

Lavergne, S., E. Garnier, and M. Debussche. 2003. Do rock endemic and widespread plant species differ under the leaf-height-seed plant ecology strategy scheme? Ecology Letters 6:398-404.

Lentner, M., and T. Bishop. 1993. Experimental design and analysis. 2nd ed. Blacksburg, VA: Valley Book. 585 p.

LICHTER, J. 2000. Colonization constraints during primary succession on coastal Lake Michigan sand dunes. Journal of Ecology 88:825-839.

Martinez, M. L., and P. Moreno-Casasola. 1996. Effects of burial by sand on seedling growth and survival in six tropical sand dune species from the Gulf of Mexico. Journal of Coastal Research 12:406-419.

Maun, M. A. 1998. Adaptations of plants to burial in coastal sand dunes. Canadian Journal of Botany 76:713-738.

MoeuR, M. 1997. Spatial analysis of competition and gap dynamics in old growth Tsuga heterophylla/Thuja plicata forests. Forest Ecology and Management 94:175-186.
Moreno-Casasola, P. 1988. Patterns of plant species distribution on coastal dunes along the Gulf of Mexico. Journal of Biogeography 15:787-806.

Oosting, H. J. 1945. Tolerance to salt spray of plants of coastal dunes. Ecology 26:85-89.

Oosting, H. J., AND W. D. Billings. 1942. Factors effecting vegetational zonation on coastal dunes. Ecology 23:131-142.

Owen, N. W., M. Kent, And M. P. Dale. 2001. Spatial and temporal variability in seed dynamics of machair sand dune plant communities, the Outer Hebrides, Scotland. Journal of Biogeography 28:565-588.

Pelissier, R., and F. Goreaud. 2001. A practical approach to the study of spatial structure in simple cases of heterogeneous vegetation. Journal of Vegetation Science 12:99-108.

Phillips, J. 1934. Succession, development, the climax, and the complex organism: an analysis of concepts, part I. Journal of Ecology 22:554-571.

Pierre, C., S. Josiane, and C. Joel. 2003. A test for spatial relationships between neighbouring plants in plots of heterogeneous plant density. Journal of Vegetation Science 14:163-172.

Pierce, W. G., and K. A. Kershaw. 1975. Studies on lichen-dominated systems. XVII. The colonization of young raised beaches in NW Ontario. Canadian Journal of Botany 54:1672-1683.

Poulson, T. L. 1999. Autogenic, allogenic, and individualistic mechanisms of dune succession at Miller, Indiana. Natural Areas Journal 19:172-176.

Psuty, N. P. 1992. Spatial variation in coastal foredune development. In: R. G. Carter, T. F. Curtis, and M. J. Sheehy-Skeffington [EDS.]. Coastal dunes. Rotterdam, Amsterdam: A. A. Balkema. p. 3-13.

Pugnaire, F. I., And M. T. Luque. 2001. Changes in plant interactions along a gradient of environmental stress. Oikos 93:42-49.

RIPLEY, B. D. 1976. The second-order analysis of stationary processes. Journal of Applied Probability 13:255-266.

RiPLEY, B. D. 1981. Spatial Statistics. New York, NY: J. Wiley. 252 p.

Schat, H., and K. van Beckhoven. 1991. Water as a stress factor in the coastal dune system. In: J. Rozema and J. A. C. Verkleij [EDs.]. Ecological responses to environmental stresses. Dordrecht, Netherlands: Kluwer. p. 76-89.

Shao, G. F., H. H. Shugart, and B. P. Hayden. 1996. Functional classifications for coastal barrier island vegetation. Journal of Vegetation Science 7:391-396.

Silander, J. A., and J. Antonovics. 1982. Analysis of interspecific interactions in a coastal plant community-a perturbation approach. Nature 298:557560.

van der Veen, A., A. P. Grootjans, J. de Jong, and J. Rozema. 1997. Reconstruction of an interrupted primary beach plain succession using a geographical information system. Journal of Coastal Conservation 3:71-78.

van Tooren, B. F., H. Schat, and S. J. ter Borg. 1983. Succession and fluctuation in the vegetation of a Dutch beach plain. Vegetatio 53:139-151.

Warming, E., And M. Vaht. 1909. Oecology of plants: an introduction to the study of plant communities. M. A. Groom and I. B. Balfour [translators]. Oxford, United Kingdom: Clarendon Press. $422 \mathrm{p}$.

Watt, A. S. 1947. Pattern and process in the plant community. Journal of Ecology 35:1-22.

WeBB, J. W. 1998. Common dune and saltmarsh plants of the upper Texas coast. Galveston, TX: Department of Marine Biology, Texas A \&M University. 28 p.

Westoby, M. 1998. A leaf-height-seed (LHS) plant ecology strategy scheme. Plant and Soil 199:213-217.

Westoby, M., D. S. Falster, A. T. Moles, P. A. Vesk, and I. J. Wright. 2002. Plant ecological strategies: some leading dimensions of variation between species. Annual Review of Ecology and Systematics 33:125-159.

Wiegand, T., and K. A. Moloney. 2004. Rings, circles, and null-models for point pattern analysis in ecology. Oikos 104:209-229.

Wiegand, T., K. A. Moloney, and S. J. Milton. 1998. Population dynamics, disturbance, and pattern evolution: identifying the fundamental scales of organization in a model ecosystem. American Naturalist 152:321-337.

WILSON, J. B., AND M. T. SYKes. 1999. Is zonation on coastal sand dunes determined primarily by sand burial or by salt spray? a test in New Zealand dunes. Ecology Letters 2:233-236.

Yarranton, G. A., and R. G. Morrison. 1974. Spatial dynamics of a primary succession: nucleation. Journal of Ecology 62:417-428. 